\title{
Minimal processing of iceberg lettuce has no substantial influence on the survival, attachment and internalization of E. coli 0157 and Salmonella
}

\author{
Inge Van der Linden a,*, Karina R. Avalos Llano ${ }^{\mathrm{a}, 1}$, Markus Eriksson ${ }^{\mathrm{a}}$, Winnok H. De Vos ${ }^{\mathrm{b}, \mathrm{c}}$, Els J.M. Van Damme ${ }^{\mathrm{b}}$, \\ Mieke Uyttendaele ${ }^{\mathrm{a}}$, Frank Devlieghere ${ }^{\mathrm{a}}$

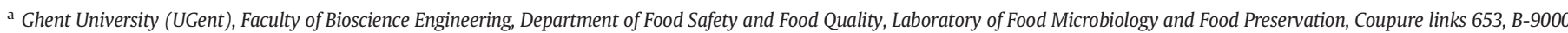 \\ Ghent, Belgium \\ ${ }^{\mathrm{b}}$ Ghent University (UGent), Faculty of Bioscience Engineering, Department of Molecular Biotechnology, Coupure links 653, B-9000 Ghent, Belgium \\ c University of Antwerp, Faculty of Pharmaceutical, Biomedical and Veterinary Sciences, Department of Veterinary Sciences, Groenenborgerlaan 171, B-2020 Antwerp, Belgium
}

\section{A R T I C L E I N F O}

\section{Article history:}

Received 26 February 2016

Received in revised form 17 June 2016

Accepted 24 July 2016

Available online 11 August 2016

\section{Keywords:}

E. coli $0157: \mathrm{H7}$

Salmonella

Attachment

Internalization

Cut Iceberg lettuce

Modified atmosphere

\begin{abstract}
A B S T R A C T
The influence of a selection of minimal processing techniques (sanitizing wash prior to packaging, modified atmosphere, storage conditions under light or in the dark) was investigated in relation to the survival of, attachment to and internalization of enteric pathogens in fresh produce. Cut Iceberg lettuce was chosen as a model for fresh produce, Escherichia coli 0157:H7 (E. coli 0157) and Salmonella enterica were chosen as pathogen models. Care was taken to simulate industrial post-harvest processing. A total of $50 \pm 0.1 \mathrm{~g}$ of fresh-cut Iceberg lettuce was packed in bags under near ambient atmospheric air with approximately $21 \% \mathrm{O}_{2}$ (NAA) conditions or equilibrium modified atmosphere with $3 \% \mathrm{O}_{2}$ (EMAP). Two lettuce pieces inoculated with E. coli O157 BRMSID 188 or Salmonella Typhimurium labeled with green fluorescent protein (GFP) were added to each package. The bags with cut lettuce were stored under either dark or light conditions for 2 days at $7{ }^{\circ} \mathrm{C}$. The pathogens' capacity to attach to the lettuce surface and cut edge was evaluated 2 days after inoculation using conventional plating technique and the internalization of the bacteria was investigated and quantified using confocal microscopy. The effect of a sanitizing wash step (40 mg/L NaClO or $40 \mathrm{mg} / \mathrm{L}$ peracetic acid $+1143 \mathrm{mg} / \mathrm{L}$ lactic acid) of the cut lettuce prior to packaging was evaluated as well. Our results indicate that both pathogens behaved similarly under the investigated conditions. Pathogen growth was not observed, nor was there any substantial influence of the investigated atmospheric conditions or light/dark storage conditions on their attachment/internalization. The pathogens attached to and internalized via cut edges and wounds, from which they were able to penetrate into the parenchyma. Internalization through the stomata into the parenchyma was not observed, although some bacteria were found in the substomatal cavity. Washing the cut edges with sanitizing agents to reduce enteric pathogen numbers was not more effective than a rinse with precooled tap water prior to packaging. Our results confirm that cut surfaces are the main risk for postharvest attachment and internalization of E. coli 0157 and Salmonella during minimal processing and that storage and packaging conditions have no important effect.
\end{abstract}

C 2016 Elsevier B.V. All rights reserved.

\section{Introduction}

Concerns have been raised about the food safety of fresh produce, such as cantaloupe, herbs, lettuce, tomatoes, spinach and sprouts, due to the fact that these items are consumed raw. Numerous outbreaks

\footnotetext{
* Corresponding author.

E-mail addresses: Inge.Vanderlinden@UGent.be, inge.vanderlinden@ugent.be (I. Van der Linden), kavalosllano@exa.unne.edu.ar (K.R. Avalos Llano),

Markus.Eriksson@UGent.be (M. Eriksson),Winnok.DeVos@UGent.be,

Winnok.devos@uantwerpen.be (W.H. De Vos), ElsJM.VanDamme@UGent.be (E.J.M. Van Damme), Mieke.Uyttendaele@UGent.be (M. Uyttendaele), Frank.Devlieghere@UGent.be (F. Devlieghere).

1 Universidad Nacional del Nordeste (UNNE), Facultad de Ciencias Exactas y Naturales y Agrimensura, Laboratorio de Tecnología Química y Bromatología, Avenida Libertad 5450, 3400 Corrientes, Argentina.
}

with Escherichia coli 0157:H7 (E. coli 0157) and Salmonella enterica have been linked to consumption of fresh produce, consequently fresh produce are considered as high-risk food by the U.S. Food and Drug Administration (Klein et al., 2009). These enteric pathogens are able to attach to and even internalize in the products which makes them very difficult to remove (Erickson, 2012). In order to improve the convenience, minimal processed bagged fresh produce products are developed relying on modified atmosphere packaging (MAP, MA packaging) and sanitizing washes to maintain quality and ensure safety of fresh produce for consumers. However, the influence of minimal processing on pathogen behavior, in particular attachment and internalization still needs further study as it is not fully known to what extent these interventions can influence the risk

By applying MAP, the respiration rate of lettuce is reduced due to the low $\mathrm{O}_{2}$ percentage in the package which retards browning and inhibits 
the outgrowth of aerobic spoilage bacteria (Posada-Izquierdo et al., 2012). It was already shown that this may induce acid resistance of $E$. coli 0157 on lettuce but only when stored at growth permissive temperatures $\left(\geq 15^{\circ} \mathrm{C}\right.$ ) (Chua et al., 2008). Furthermore, the virulence of $E$. coli 0157:H7 on MA packed lettuce at this temperature was shown to be lower in comparison with near ambient air (NAA) conditions (Sharma et al., 2011). In addition, it was demonstrated that equilibrium MA packaging (EMAP) $\left(10 \% \mathrm{O}_{2}, 10 \% \mathrm{CO}_{2}\right.$, and $\left.80 \% \mathrm{~N}_{2}\right)$ had an antimicrobial effect on indigenous lettuce microbiota, but not on Salmonella and even favored the survival of this pathogen (Horev et al., 2012). Also, growth and survival of E. coli 0157:H7 in manure and slurry were shown to be promoted under anaerobic conditions (Semenov et al., 2011). Thus far, only one study has investigated the combination of the effect of MAP (and temperature and respiration rate) on the attachment and internalization of $E$. coli 0157 in fresh cut lettuce (Takeuchi et al., 2001). In the latter study, only the cut edges of lettuce were investigated in a labscale set-up. Takeuchi et al. (2001) did not report a relation between attachment or penetration and respiration rate of the lettuce and they only found small differences in attachment between the different atmospheric conditions and temperatures.

In the present study the influence of MA packaging on the survival, attachment and internalization of Salmonella and E. coli 0157 on fresh cut Iceberg lettuce was investigated in order to identify conditions that present a lower risk to consumers such as low attachment degree of pathogens, low degree of pathogen internalization or higher susceptibility of the pathogens for sanitizers. Special attention was paid to simulate commercial MA packaging (equilibrium $\mathrm{MAP}, 3 \% \mathrm{O}_{2}, 97 \% \mathrm{~N}_{2}, 7^{\circ} \mathrm{C}$ ). As it was already shown that the attachment of the pathogen may be different for the cut edge or the surface of a cut leaf piece (Kroupitski et al., 2009b; Seo and Frank, 1999; Takeuchi and Frank, 2001; Takeuchi et al., 2000, 2001), both leaf regions were investigated. Since Kroupitski et al. (2009a) revealed that Salmonella is attracted to nutrients produced by photosynthetically active cells of cut lettuce, and bagged fresh-cut lettuces are exposed to light in food stores, storage conditions (light or dark) were taken into account as well, In addition, this effect was for the first time investigated on E. coli 0157 and cut lettuce. The classical plate count technique as well as quantitative confocal laser scanning microscopy were used in the present study to evaluate and quantify the effect of high (necessary for monitoring with confocal laser microscopy) or moderate pathogen levels. In addition, the effect of the combination of a sanitizing wash step ( $40 \mathrm{mg} / \mathrm{L} \mathrm{NaClO}$ or $40 \mathrm{mg} / \mathrm{L}$ peracetic acid $+1143 \mathrm{mg} / \mathrm{L}$ lactic acid) of the cut lettuce prior to MApackaging was studied on a selection of conditions that were identified in this study to impose a high risk of pathogen internalization.

\section{Materials and methods}

\subsection{Influence of MAP, light, cut edge/surface, and inoculum density}

\subsubsection{Bacterial strains and growth conditions}

Chromosomally green fluorescent protein (GFP) labeled Salmonella enterica (serovar Typhimurium) and E. coli 0157 strain BRMSID 188 GFP were used. The wildtype Salmonella Typhimurium was isolated from freshwater sediments and chromosomally labeled with a stable variant of GFP by means of the pUT mini-Tn5 Km transposon by tri-parental mating. The strain was kindly donated by Prof. Venter (Division of Natural Resources and the Environment, CSIR, Pretoria 0001, South Africa) and described in (Burke et al., 2008). E. coli 0157:H7 BRMSID188 GFP was kindly donated by Dr. Susan Bach (Agriculture and Agri-Food Canada, Pacific Agri-Food Research Centre, Canada) and described in (Dinu and Bach, 2011). Briefly, the wild type was isolated from bovine and chromosomally labeled with a stable variant of GFP by means of Tn7-transposon. Both strains are resistant against $100 \mu \mathrm{g} / \mathrm{mL}$ kanamycin.

Reference stocks were stored at $-75^{\circ} \mathrm{C}$ in tryptone soy broth (TSB; Oxoid, Basingstoke, England), supplemented with $50 \mu \mathrm{g} / \mathrm{mL}$ kanamycin
(TSB-K) and 15\% glycerol (Prolabo, Heverlee, Belgium). Stock cultures were kept at $4{ }^{\circ} \mathrm{C}$ on tryptone soy agar (TSA, Oxoid, Basingstoke, England) slants supplemented with $50 \mu \mathrm{g} / \mathrm{mL}$ kanamycin (TSA-K). Working cultures were prepared by loop inoculation in $10 \mathrm{~mL}$ of TSB-K and statically incubated for $6 \pm 1 \mathrm{~h}$ at $37^{\circ} \mathrm{C}$. Then, $2 \mathrm{~mL}$ of this inoculum was transferred to $200 \mathrm{~mL}$ TSB-K in a $500 \mathrm{~mL}$ bottle and incubated at $37^{\circ} \mathrm{C}$ for $18 \pm 1 \mathrm{~h}$, using an orbital shaker (200 rpm, Yellowline RS/OS 10 Control, IKA-Werke GmbH\&Co, Staufen, Germany).

The optical density $(650 \mathrm{~nm})$ of the bacterial cultures was measured in triplicate in a 96-well plate using a spectrophotometer (Versamax, Molecular Devices, Wokingham, UK). Bacterial suspensions ( $\log$ 9.5 CFU/mL or $\sim \log 5.5 \mathrm{CFU} / \mathrm{mL}$ ) were washed twice with sterile distilled water by centrifugation $(2900 \times g$ for $10 \mathrm{~min}$ at room temperature) (Sigma 4K15, SIGMA Laborzentrifugen $\mathrm{GmbH}$, Osterode am Harz, Germany). Cells in the pellet were resuspended in $100 \mathrm{~mL}$ sterile distilled water and the bacterial suspension was stored at $7{ }^{\circ} \mathrm{C}$ until use ( $\max 1 \mathrm{~h}$ ). The cell population of the inoculum was determined by plating 10 -fold serial dilutions in physiological peptone salt solution (PPS) on TSA-K $\left(18-24 \mathrm{~h}, 37^{\circ} \mathrm{C}\right)$.

\subsubsection{Inoculation of lettuce pieces}

Iceberg lettuce was obtained from a local vegetable supplier (Ghent, Belgium). The lettuce heads were weighed, cut in two and the maturity stage was determined based on the lettuce head density chart. The three (for younger maturity stage) or four to five (for higher maturity stage) outer leaves of the lettuce were removed. The next three leaves were used to cut leaf pieces of approximately $4.5 \mathrm{~cm} \times 4.5 \mathrm{~cm}$ on the top-region of the leaf (Fig. 1). A triangular mark was cut out in the lower left corner of the lettuce piece, when the lettuce piece was lying with the abaxial side on the cutting board and with the top ruffle of the leaf facing away from the operator. Subsequently, the leaf pieces were inoculated by submerging them individually for $2 \mathrm{~s}$ in the bacterial suspension using a sterile forceps. Afterwards, the leaf pieces were drained on a paper towel to remove the excess of bacterial suspension and stored at $7{ }^{\circ} \mathrm{C}$ until packed ( $\left.\max 1 \mathrm{~h}\right)$.

\subsubsection{Minimal processing of uninoculated lettuce}

Iceberg lettuce was processed as described by Lopez-Galvez et al. (2013) with some modifications. Briefly, after its reception in the lab, lettuce was kept at $4{ }^{\circ} \mathrm{C}$ for max. $2 \mathrm{~h}$ before processing. Outer leaves and core were removed and lettuce was cut in pieces of approximately $4.5 \mathrm{~cm} \times 4.5 \mathrm{~cm}$ by means of stainless steel knives in clean conditions. About $1 \mathrm{~kg}$ of untreated fresh-cut lettuce was washed in $10 \mathrm{~L}$ cold tap water $\left(7^{\circ} \mathrm{C}\right)$ for $1 \mathrm{~min}$. Subsequently, the product was rinsed again in $10 \mathrm{~L}$ tap water at $7{ }^{\circ} \mathrm{C}$ for $1 \mathrm{~min}$. Finally, the cut lettuce was drained by centrifuging for $1 \mathrm{~min}$ using a manually operated centrifuge (16 L). All the processing steps were performed in a cold room at $7{ }^{\circ} \mathrm{C}$.

\subsubsection{Packaging and storage}

In the current study a fill weight of $50 \pm 0.1 \mathrm{~g}$ was used. Therefore, the bags $(19 \mathrm{~cm} \times 19 \mathrm{~cm})$ were first filled with $\pm 25 \mathrm{~g}$ of uninoculated minimally processed lettuce. Subsequently, two inoculated leaf pieces $(1.7 \pm 0.7 \mathrm{~g})$ were added to the bag with a sterile forceps and the bag was further filled with uninoculated minimally processed lettuce until a weight of $50 \pm 0.1 \mathrm{~g}$ was reached. Equilibrated modified atmosphere packaging (EMAP, $3 \% \mathrm{O}_{2}, 97 \% \mathrm{~N}_{2}$ ) conditions were performed with a packaging foil (60 LB PLAIN, Amcor-Flexibles, Ledbury, Herefordshire, UK) with an $\mathrm{O}_{2}$ permeability of $1000 \mathrm{~mL} \mathrm{O}_{2} / \mathrm{m}^{2} \cdot \mathrm{d} \cdot \mathrm{atm}$ measured at ASTM D1434, $23{ }^{\circ} \mathrm{C}, 0 \% \mathrm{RH}$. The foil consisted of a $30 \mu \mathrm{m}$ printable clear polypropylene layer and a $30 \mu \mathrm{m}$ clear polyethylene layer. Then, the packages were flushed with $2.5-3 \% \mathrm{O}_{2}$ (Freshline, Air Products, Brussels, Belgium) and 97-97.5\% N 2 (RT-X50S-Food, Air Products, Brussels, Belgium) as initial gas atmosphere by means of a gas packaging unit consisting of a gas mixer (WITT KM 100-4 MEM, Witt-Gasetechnic, Witten, Germany). The near ambient air atmospheric (NAA) conditions were realized with a high barrier packaging foil (NX90, Euralpack, 

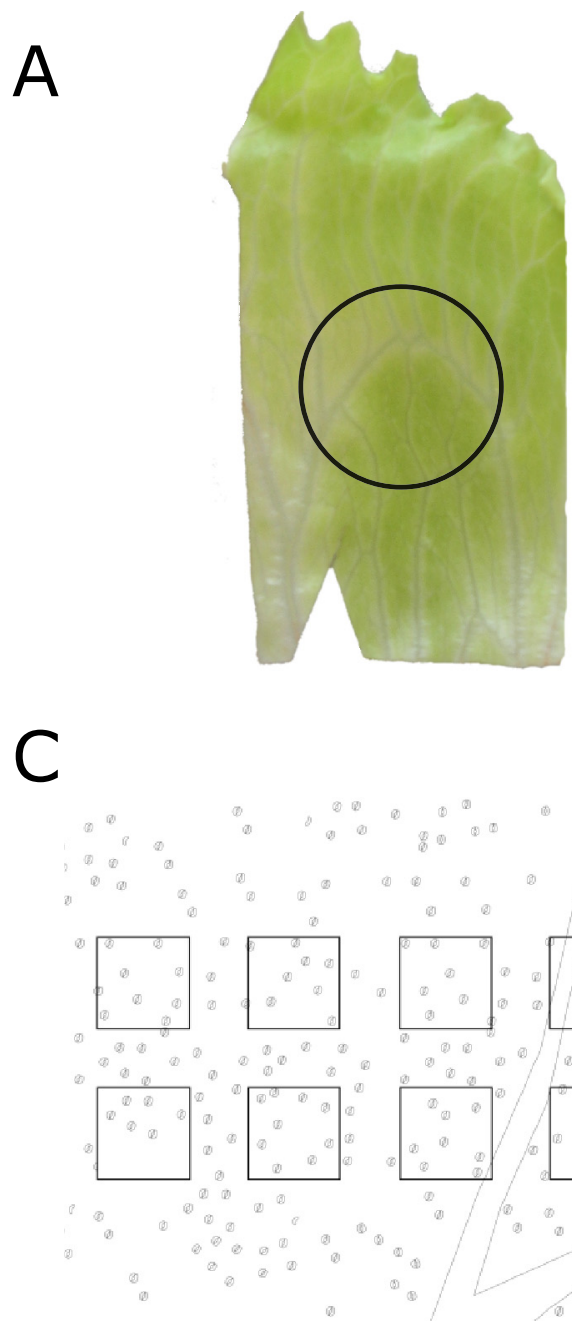

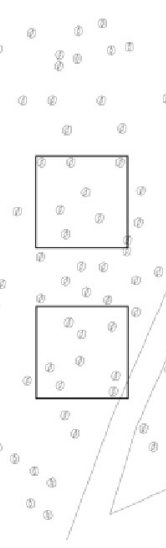

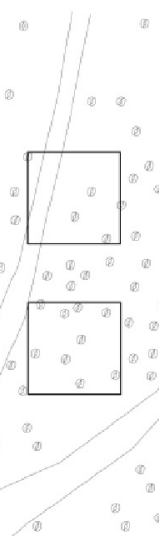

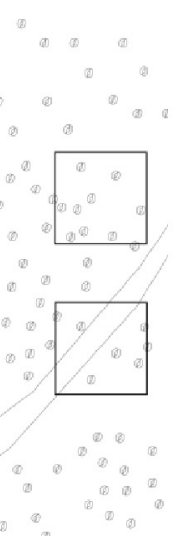

B

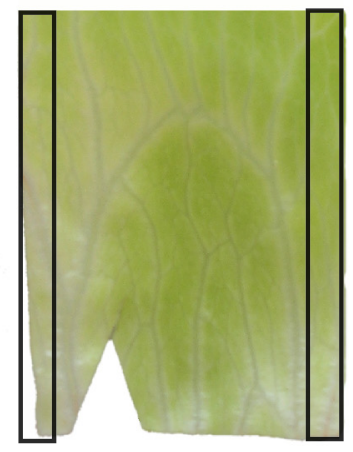

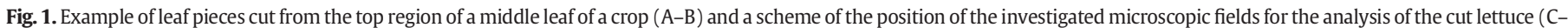

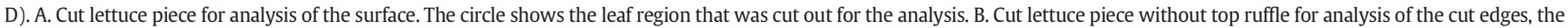

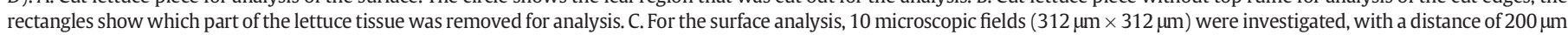

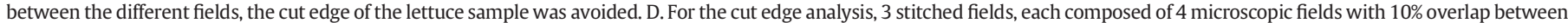
the fields, were investigated. The uttermost left field contained the cut edge. The stitched fields were also $200 \mu \mathrm{m}$ separated from each other.

Schoten, Belgium) with the same dimensions as the EMAP bags. The $\mathrm{O}_{2}$ permeability of the foil was $2.0 \mathrm{O}_{2} / \mathrm{m}^{2} \cdot \mathrm{d} \cdot$ atm measured at $23{ }^{\circ} \mathrm{C}, 85 \% \mathrm{RH}$ and the foil had a thickness of $90 \mu \mathrm{m}$. An air pipe with a diameter of approximately $1 \mathrm{~cm}$ was made in the package to create near-ambient air (NAA) atmospheric conditions. After packaging, the packages were stored at $7{ }^{\circ} \mathrm{C}$ for 2 days either in dark or in light conditions. For the light conditions, the bags were lying $80 \mathrm{~cm}$ below commercial fluorescent lamps (Mastec 36 Watt Cool Winter 33 CLT 52/09). The light intensity was measured using a Lux meter (PAR-cell 532; 400-700 nm, Skye Instruments, Llandrindod Wells, UK). The lettuce bags in dark conditions were stored in a non-airtight, non-transparent box with a lid.

\subsubsection{Headspace gas analysis}

Oxygen and carbon dioxide concentrations were measured in each bag for each treatment at each sampling time. Measurements were performed by means of the Checkmate gas analyzer (CheckMate 9900, PBI Dansensor, Ringsted, Denmark).

\subsubsection{Lettuce analysis and attachment assay}

At 1-3 h (day 0 ) and 2 days after packaging, the pathogen numbers on the inoculated lettuce pieces were determined. Each day, one bag was used for each condition that was studied. The content of a bag was emptied in a tray and the two inoculated lettuce pieces were taken with sterile forceps. Both the cut edges and the surface were analyzed (in independent experiments). For the surface analysis, leaf discs ( $2.7 \mathrm{~cm}$ in diameter) were cut out from the middle of the lettuce piece using the rounding of an aseptic $50 \mathrm{~mL}$ polypropylene tube as a template. For the cut edges, two strips with a size of approximately $0.5 \mathrm{~cm} \times 4.5 \mathrm{~cm}$ on the left and right sides of the lettuce piece were removed with a sterile scalpel. For the analysis of the total number of bacteria associated with the lettuce, the leaf region of interest (surface or cut edge) was transferred into $4 \mathrm{~mL}$ PBS $+0.05 \%$ Tween 20 in sterile filter bags (Extraction bags Universal $12 \times 15 \mathrm{~cm}$, Bioreba, Reinach, Switzerland). The bags were sealed, weighed and the lettuce was grinded (Handheld Homex, Bioreba, Reinach, Switzerland) until a homogenous mixture was obtained. The bacterial suspension was serially diluted in PPS and the number of CFU was determined by spread plating on TSA$\mathrm{K}\left(18-24 \mathrm{~h}, 37^{\circ} \mathrm{C}\right)$. To determine the number of bacteria that were attached and/or internalized to the lettuce, an attachment assay was performed as described by Van der Linden et al. (2014) with minor modifications. Briefly, each lettuce piece (leaf disc or two cut edges) was rinsed twice for $1 \mathrm{~min}$ each in $75 \mathrm{~mL}$ SDW to remove unattached bacteria. The washed discs or cut edges were transferred into $4 \mathrm{~mL}$ PBS $+0.05 \%$ Tween 20 in sterile filter bags and analyzed as described for the "total number of bacteria on the lettuce piece". With the plate count technique it was not possible to distinguish between internalized 
and attached pathogens. For each studied condition, two lettuce pieces (from the same package) were investigated separately and three independent experiments were performed $(n=6)$.

\subsubsection{Internalization assay}

Microscopic slides were prepared by gluing an open square of $2.2 \mathrm{~cm} \times 2.2 \mathrm{~cm}$ with an edge of $0.5 \mathrm{~cm}$ (Stop pressions, Hansaplast Food Expert, Beiersdorf, Hamburg, Germany). A double-sided transparent tape was stuck in the middle of the microscopic slide. A leaf piece of approximately $0.5 \mathrm{~cm} \times 0.5 \mathrm{~cm}$ was cut from the middle (surface) or the edge (cut edges) of the inoculated lettuce piece (high inoculum density). The lettuce pieces were mounted on the double-sided transparent tape on the microscopic slide with the abaxial side of the leaf upwards (side that was investigated). Approximately $50 \mu \mathrm{L}$ of $2 \mu \mathrm{g} / \mathrm{mL}$ solution of Nile Red (72485-100MG, Sigma Aldrich, S. Louis, MO, USA) was added on the lettuce and the microscopic slide was sealed with nail polish and a cover glass. The samples were examined using a Nikon A1R confocal laser scanning microscope (Nikon Inc., Melville, NY, USA), mounted on a Nikon Ti epifluorescence body. A $488 \mathrm{~nm}$ Ar laser was used for excitation. GFP emission was detected between $505 \mathrm{~nm}-$ $525 \mathrm{~nm}$, autofluorescence was detected between 690 and $710 \mathrm{~nm}$, and Nile Red emission between $710 \mathrm{~nm}-850 \mathrm{~nm}$. The same excitation line was used for simultaneous Differential Interference Phase Contrast (DIC) imaging.

For the analysis of the surface 10 microscopic fields with a physical size of $312 \mu \mathrm{m} \times 312 \mu \mathrm{m}$ were investigated in two rows of 5 fields, separated by $200 \mu \mathrm{m}$. For each field, the total number of stomata and the number of stomata with $1,2,3,4,5-10$ or $>10$ pathogens inside the stomata were counted. The presence of pathogens in the parenchyma was investigated by making confocal Z-stacks down to $50 \mu \mathrm{m}$ below the cuticula (recognized by Nile Red fluorescence which stained cuticula and guard cells of the stomata). The surface of the lettuce was analyzed for each combination of light, pathogen and packaging conditions. For each tested condition one lettuce piece was analyzed at day 0 and day 2. The surface experiments were repeated five times.

For the analysis of the cut edge, four fields were horizontally stitched as shown in Fig. 1. The first field contained the cut edge itself. For each cut edge, three stitched pictures, vertically separated at least $200 \mu \mathrm{m}$ from each other were taken. A depth scan (Z-scan) was performed and each $2.5 \mu \mathrm{m}$ an image was taken up to $20 \mu \mathrm{m}$ below the lowest point of the cuticula. The cut edge of the lettuce was analyzed for each combination of pathogen species and packaging condition stored in the dark. For each tested condition one lettuce piece was analyzed at day 0 and day 2 . The cut edge experiment was repeated twice.

\subsubsection{Statistical analysis}

Plate count data were $\log _{10}$ transformed and analyzed with one-way ANOVA performed for each combination of pathogen (E. coli 0157/Salmonella), inoculum level (high/low), storage condition (light/dark) and lettuce region (surface/cut edge) with the combination of total/attached, day, and atmospheric conditions (EMAP or NAA) as groups in the analysis at $\mathrm{P}<0.05$. Scheffé was performed as post hoc test. Confocal microscopy data of the lettuce surface were analyzed for the percentage of stomata per investigated leaf piece with at least one associated pathogen in comparison with the total number of stomata. The experiments with E. coli 0157 were analyzed with general linear model procedure (GLM). The analysis started with a saturated model and non-significant terms were sequentially dropped at a significance level of 0.05 . The most parsimonious model was used when analyzing the data, this was the model with only the main factors. Since confocal microscopy data for Salmonella did not fulfil the requirements of equality of variances, pairwise analysis was performed with Kruskall-Wallis non-parametric test at $\mathrm{P}<0.05$. The influence of atmospheric condition was tested for each combination of day and storage condition, the influence of storage condition (light/dark) for each combination of atmospheric condition and day and the influence of storage time for each combination of atmospheric and storage condition. SPSS version 20 (IBM) was used for all tests. Graphs were made with Matlab v. 8.3.

\subsection{Sanitizing experiment}

\subsubsection{Bacterial strains and growth conditions}

The inocula were prepared as described in 2.1.1.

\subsubsection{Inoculation of lettuce pieces}

The inoculated lettuce pieces were prepared as described in 2.1.2 with some minor modifications: the leaf pieces were stored at $7{ }^{\circ} \mathrm{C}$ for at least $30 \mathrm{~min}$ and $\max 1 \mathrm{~h}$ at $7{ }^{\circ} \mathrm{C}$ before the (sanitizing) washing step.

\subsubsection{Preparation of sanitizing solutions}

Two different sanitizer solutions were tested with tap water as control treatment. The first sanitizer tested was a combination of peracetic acid (PAA) (32\% wt. in dilute acetic acid, ref. nr. 269336, Sigma-Aldrich) and lactic acid (LA) (approximately 50\%, Purac, Gorinchem, The Netherlands). The solution was prepared by adding PAA and LA to $10 \mathrm{~L}$ precooled tap water $\left(7^{\circ} \mathrm{C}\right)$ to achieve a concentration of $40 \mathrm{mg} / \mathrm{L}$ and $1143 \mathrm{mg} / \mathrm{L}$, respectively. The PAA concentrations were calculated based on the immediate measurement of the total chlorine by means of the HI93711 meter (Hanna instruments, Temse, Belgium). A conversion factor for PAA was previously determined to be $84.7 \%$ of the measured value of the measured total chlorine value. Due to changes in equilibrium and stability of the solution, the concentrations had to be adjusted for each experiment. This was done either by adding more disinfectant to the solution or by removing a part of the solution and adding more tap water. The second sanitizer was a $40 \mathrm{mg} / \mathrm{L}$ sodium hypochlorite solution. Sodium hypochlorite $\left(\mathrm{NaClO}, 3.5 \% \mathrm{Cl}_{2}\right.$ in aqueous solution. ref. nr. 27896.291, VWR International, Leuven, Belgium) was diluted in $10 \mathrm{~L}$ precooled tap water $\left(7^{\circ} \mathrm{C}\right)$ to get a free chlorine concentration of $40 \mathrm{mg} / \mathrm{L}$. The free chlorine concentration was immediately measured using the HI93711 meter. The control treatment consisted of $10 \mathrm{~L}$ precooled tap water $\left(7^{\circ} \mathrm{C}\right)$. After preparation of the sanitizers, a volume of $100 \mathrm{~mL}$ was removed from each solution and added to a small $180 \mathrm{~mL}$ sterile sample container and stored at $7^{\circ} \mathrm{C}$.

\subsubsection{Sanitizer treatment of inoculated lettuce pieces}

Four lettuce pieces (prior stored at $7{ }^{\circ} \mathrm{C}$ ) were added to $100 \mathrm{~mL}$ of the sanitizer solution (or tap water as control) (prior stored at $7{ }^{\circ} \mathrm{C}$ ). The container was regularly swirled to optimize the washing process. After $1 \mathrm{~min}$ the sanitizing solution was decanted, $100 \mathrm{~mL}$ cold tap water was added and the rinsing procedure was repeated.

\subsubsection{Minimal processing of uninoculated lettuce}

Iceberg lettuce was processed as described in 2.1.3 with some minor changes. Then, $500 \mathrm{~g}$ (instead of $1 \mathrm{~kg}$ ) of untreated fresh-cut lettuce was washed in $10 \mathrm{~L}$ cold sanitizer solution $\left(7^{\circ} \mathrm{C}\right.$ ) or tap water (control treatment) for $1 \mathrm{~min}$. Subsequently, the product was rinsed in $10 \mathrm{~L}$ fresh tap water at $7{ }^{\circ} \mathrm{C}$ for $1 \mathrm{~min}$, and drained as described in 2.1.3.

\subsubsection{Packaging and storage}

Lettuce was packed as described in 2.1.4 but PAA + LA treated uninoculated lettuce was combined with PAA + LA treated inoculated lettuce pieces, $\mathrm{NaClO}$ treated uninoculated lettuce with $\mathrm{NaClO}$ treated inoculated lettuce pieces, and tap water treated uninoculated lettuce was combined with tap water treated inoculated lettuce pieces (control). After packaging, the packages were stored at $7{ }^{\circ} \mathrm{C}$ for 2 days in dark conditions.

\subsubsection{Headspace gas analysis}

The headspace gas analysis was performed as described in 2.1.5. 


\subsubsection{Lettuce analysis and attachment assay}

The inoculated lettuce pieces were analyzed as described in 2.1 .6 but only the cut edges were analyzed and no extra rinsing step ("attached pathogens") was performed since the loosely attached pathogens were already removed during the sanitizer treatment.

\subsubsection{Statistical analysis}

The data were analyzed with one way ANOVA performed for each combination of pathogen and inoculum level with the combination of sanitizing treatment and storage time as groups in the analysis at $\mathrm{P}<0.05$ in SPSS version 20 (IBM). Scheffé was performed as post hoc test. Graphs were made with Matlab v. 8.3.

\section{Results}

\subsection{Influence of EMAP, light, cut edge/surface, and inoculum density}

\subsubsection{Influence of atmospheric conditions}

The atmospheric conditions in the bagged Iceberg lettuce, EMAP versus NAA, did not show any significant influence on the survival and attachment/internalization (as determined by plate counting collecting cells from surface and cut edge region) (Figs. 2 and 3) or internalization (as determined by confocal microscopy visualizing cells on the surface region) (Fig. 4) for any of the tested conditions.

\subsubsection{Difference cut edge vs. surface region}

A clear difference in the attachment/internalization of the pathogens was observed between the cut edges and the surface region of the Iceberg lettuce pieces (Fig. 2 compared to Fig. 3). The classical plate counting assay showed that washing removed around $1 \log \mathrm{CFU} / \mathrm{leaf}$ disc from the surface and around $0.5 \log \mathrm{CFU} /$ cut edges from the cut edges when the leaf pieces were inoculated with a high pathogen inoculum. When the leaf pieces were inoculated with a low inoculum, a relatively lower number of pathogens were removed from the lettuce pieces, which was especially clear for the cut edges inoculated with $E$. coli 0157. A decrease of only 0.09-0.16 log CFU/cut edges was noted after washing. Washing of the surface region of the lettuce, reduced the number of pathogens significantly for all tested conditions. For the cut edges in general no significant effect was observed between the number of pathogens before (total) and after washing (attached/internalized) except for the high inoculum of E. coli 0157 at day 0 NAA and day 2 EMAP. Confocal microscopy revealed that the pathogens were able to internalize into the parenchyma through the cut edges (Fig. $5 \mathrm{~F}-\mathrm{J}$ ). However, internalization in the parenchyma was never observed when the leaf surface was investigated, except in those cases where the tissue was clearly wounded. Therefore, these results were not taken into account. The pathogen was only found in the substomatal cavities of the leaves (Fig. 5B, C and E). In the majority of the cases, only one pathogen was found associated (on average 53.1\% for Salmonella, 43.1\% for E. coli 0157) but occasionally $>10$ bacteria were found (Fig. 5C).

\subsubsection{Influence light/dark storage}

The effect of storage in light vs. dark was only tested on the surface of the leaf pieces since the main goal of this experiment was to study the influence of light on the internalization of the pathogen through the stomata. Using the classical plate counting technique, no significant differences were observed for the survival and attachment/internalization of pathogens in the packages stored in light and dark conditions (Fig. 2). Although small differences in the association of the pathogens with the stomata were observed by confocal microscopy, none of these differences were statistically significant (Fig. 4). On average a higher level of Salmonella was found associated with (at least one) stomata when the lettuce bags were stored in the light compared to the dark at both time points. For $E$. coli 0157 , however, this effect was mainly observed at day 2 . The association of the pathogens with the stomata was highly variable between the five independent repeats (see also supplemental Fig. S1 and Table S1).

\subsubsection{Influence of storage time}

For none of the studied conditions, storage time had a significant effect on the survival and attachment/internalization as determined by classical plating method (Figs. 2 and 3). When the lettuce surfaces were analyzed with the confocal microscope, an increased number of E. coli $0157(\mathrm{P}<0.05)$ associated with the stomata was found at day 2. No significant increase of Salmonella was found (Fig. 4).

\subsubsection{Salmonella vs. E. coli 0157}

In general, a quite similar behavior was observed for both pathogens under study. On average a higher number of $E$. coli 0157 were removed from the lettuce samples compared to samples inoculated with Salmonella, except for the experiment where a low inoculum of E. coli 0157 was used (Figs. 2 and 3). Furthermore, the initial association of the pathogens with stomata was on average 1.8 times higher for Salmonella in comparison with $E$. coli 0157 (23.4\% of stomata with at least one pathogen resp. 13.03\%). This observation could be explained by the difference in inoculum level that was on average 2.3 times higher for Salmonella $(9.73 \pm 0.18 \log \mathrm{CFU} / \mathrm{mL})$ compared to E. coli 0157 $(9.39 \pm 0.12 \log \mathrm{CFU} / \mathrm{mL})$ (Fig. 4).

\subsection{Sanitizing wash}

The results shown in Fig. 6 revealed no difference in effectiveness of removing the pathogen from the cut edge between the three different treatments on lettuce pieces inoculated with high or low inoculum of E. coli 0157:H7 BRMSID 188 and low inoculum of Salmonella Typhimurium. Rinsing with tap water was as effective as rinsing with $40 \mathrm{mg} / \mathrm{L} \mathrm{PAA}+1143 \mathrm{mg} / \mathrm{L} \mathrm{LA}$ or $40 \mathrm{mg} / \mathrm{L} \mathrm{NaClO}$. For lettuce pieces inoculated with a high Salmonella level, the PAA + LA treatment reduced the number of pathogens on the cut edges significantly with around $0.5 \log$ $\mathrm{CFU} / \mathrm{cut}$ edge in comparison with the control tap water rinse. Storage time had no significant effect for none of the tested conditions.

\section{Discussion}

In this study, the effects of packaging conditions (EMAP/NAA) and storage conditions (light/dark) on survival of, attachment to and internalization of enteric pathogens in fresh cut Iceberg lettuce were investigated. Since pathogens were most persistent at the cut edges, the influence of an additional sanitizer wash prior to packaging was tested as well.

To the knowledge of the authors, only one study performed by Takeuchi et al. (2001) investigated the influence of modified atmosphere on the attachment and internalization of E. coli 0157 onto/into lettuce (Takeuchi et al., 2001). They reported a marginal difference in attachment/internalization between storage at NAA $\left(\sim 21 \% \mathrm{O}_{2}\right)$ and storage in an atmosphere with reduced $\mathrm{O}_{2}(2.7 \%)$ levels, at the cut edges at different temperatures of storage $\left(4{ }^{\circ} \mathrm{C}, 22^{\circ} \mathrm{C}, 37^{\circ} \mathrm{C}\right)$. They also found that $\mathrm{E}$. coli $\mathrm{O} 157$ was able to penetrate deeper into the cut edges at NAA but no correlation was found with the respiration rate of lettuce (which is lower at lower oxygen concentrations). Our plate count results of the cut edges did not point towards a significant influence of atmospheric conditions on the attachment/internalization of Salmonella and E. coli 0157. However, the plate count technique is not sensitive enough to pick-up the small differences, as observed by Takeuchi et al. through confocal microscopy. But we were not yet able to investigate our cut edge data obtained by confocal microscopy in a quantitative way as it was difficult to define the starting point of the cut edge in a standardized way for all Zscans and to be sure that the pathogens were not internalized through other wounds. In addition to the work of Takeuchi et al., we also studied the attachment/internalization of the pathogens at 
E. coli 0157

High inoculum / Dark storage

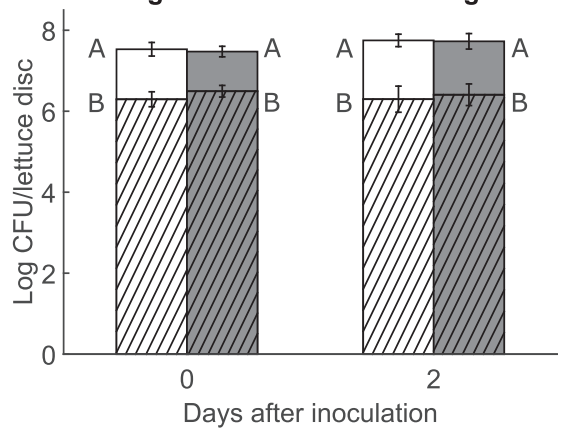

E. coli 0157

High inoculum / Light storage

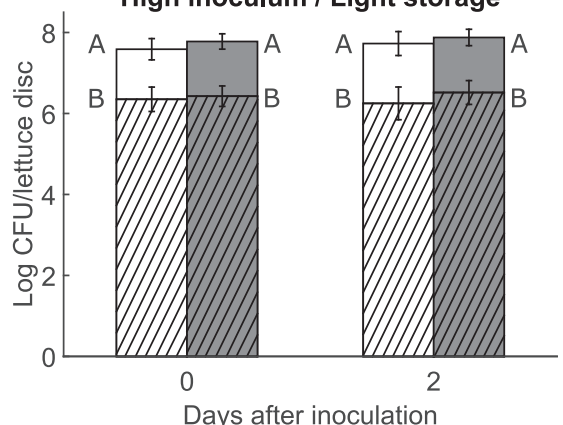

Salmonella

High inoculum / Dark storage

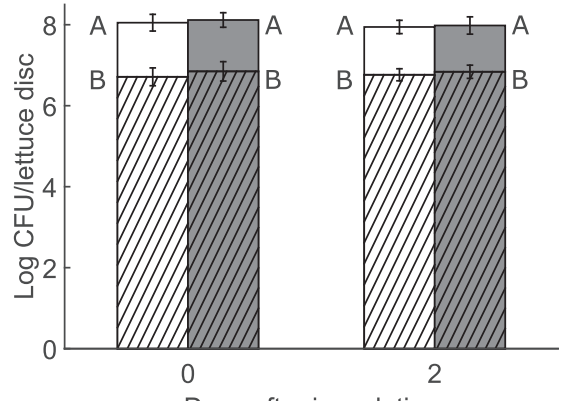

Days after inoculation

Salmonella

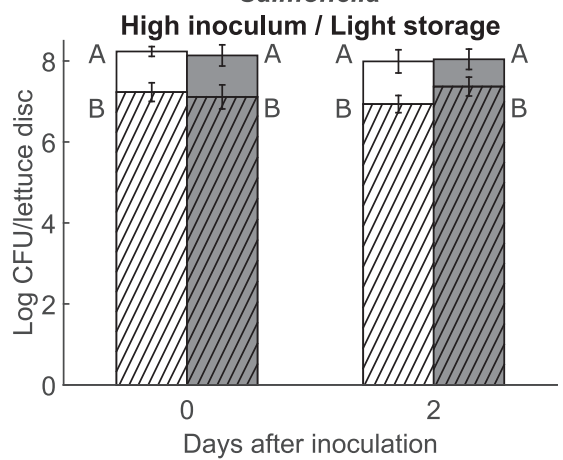

E. coli 0157

Low inoculum / Dark storage

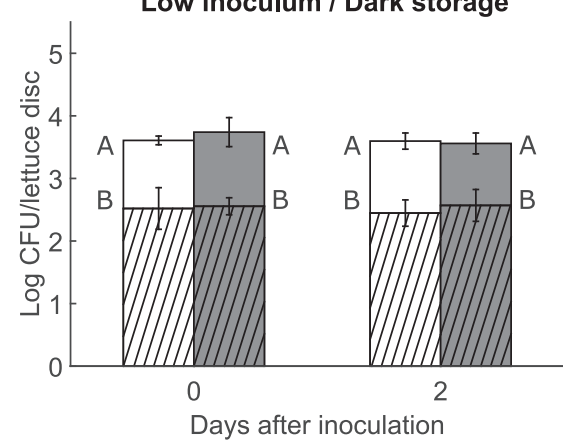

E. coli 0157

Low inoculum / Light storage

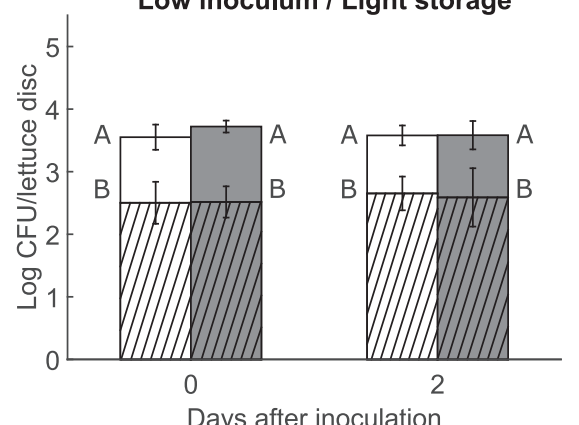

Salmonella

Low inoculum / Dark storage

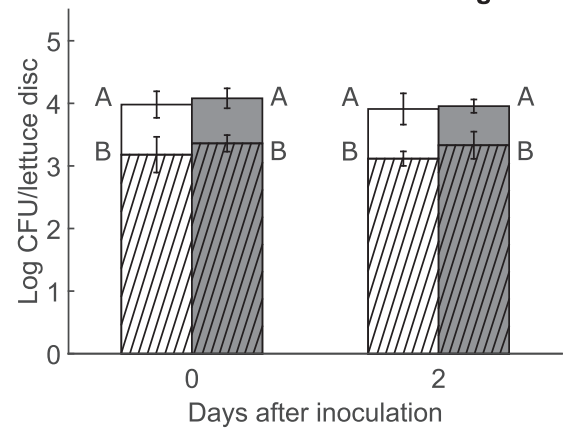

Salmonella

Low inoculum / Light storage

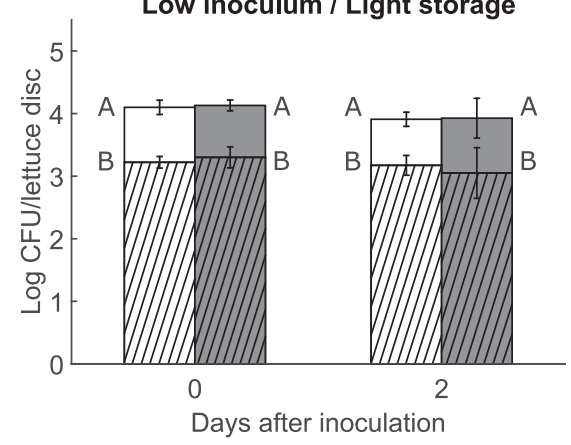

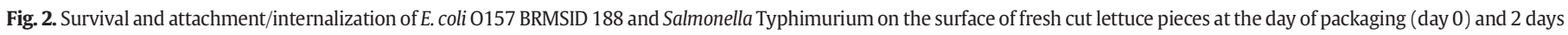

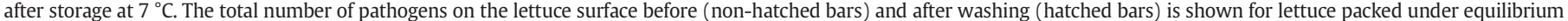

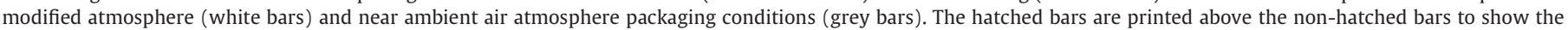

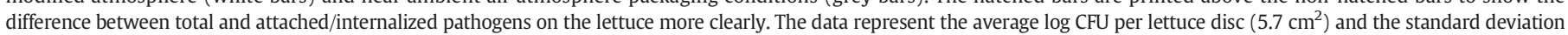

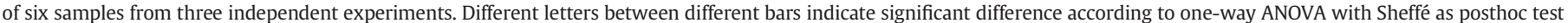
$(\mathrm{P}<0.05)$.

the intact surface, and the confocal microscopy data were analyzed quantitatively as we were able to stain the cuticula and stomata (a reference for the surface). Both results (confocal microscopy and plate counting) did not reveal a significant effect of the atmospheric packaging conditions on the attachment/internalization of the pathogens associated with the intact surface. 


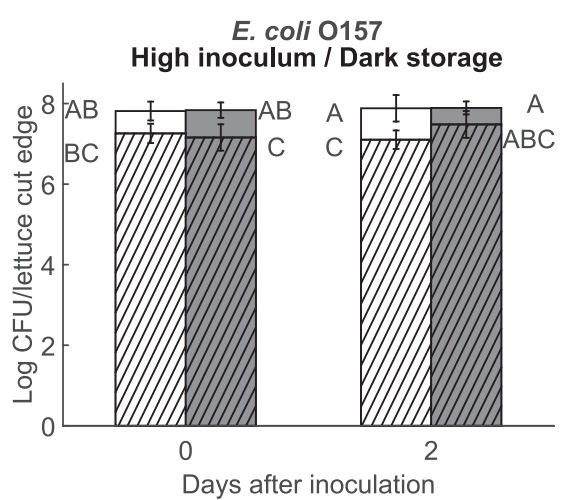

Salmonella High inoculum / Dark storage

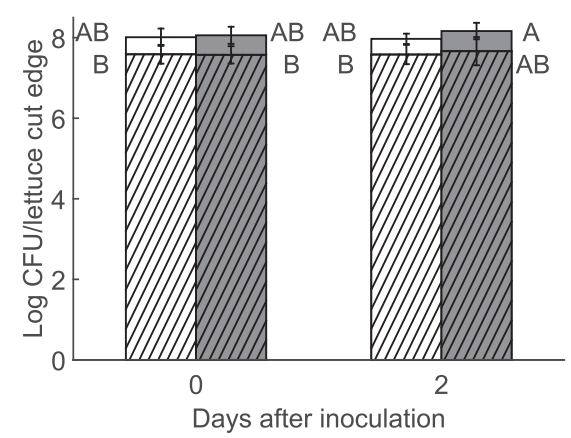

E. coli 0157

Low inoculum / Dark storage

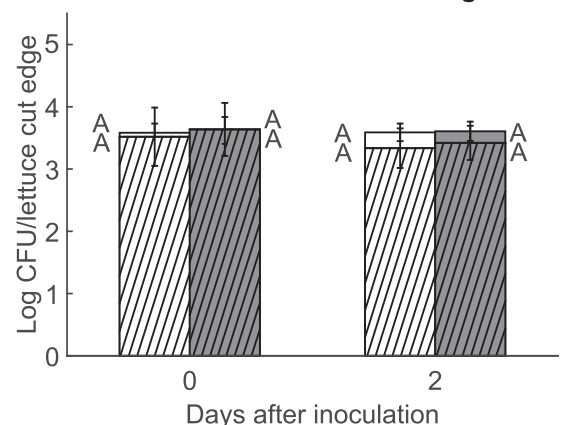

Salmonella

Low inoculum / Dark storage

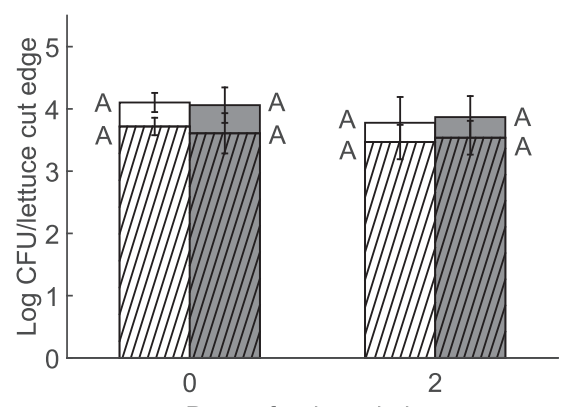

Days after inoculation

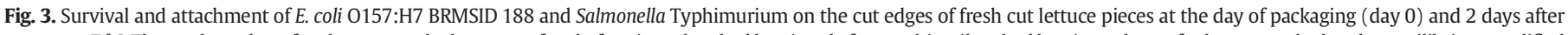

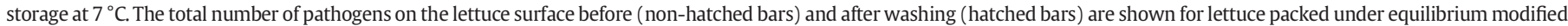

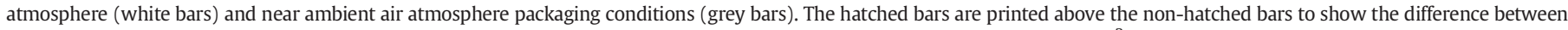

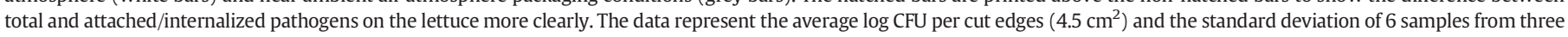
independent experiments. Different letters between different bars indicate significant difference according to one-way ANOVA with Sheffé as posthoc test (P $<0.05$ ).

By analyzing both internalization through stomata and cut edge, two different ways of post-harvest internalization of the pathogen into a leaf were investigated. A third internalization way through hydathodes, which are permanently open water pores in the epidermis or leaf margin and are directly connected to the plant vascular system, was not investigated in our study as in the case of case of cut lettuce, the cut edge seemed to be a more important internalization route due to the higher surface of cut tissue compared to hydathode openings. Hydathodes can, however, be an important pre-harvest internalization route for e.g. Salmonella in growing tomato plants (Gu et al., 2013).

The plate counting data showed that there was a difference in the degree of attachment/internalization between the surface and the cut edge for both studied pathogens. E. coli 0157:H7 BRMSID 188 was least efficiently removed from the cut edge, especially when (relatively) low pathogen levels were used (Takeuchi et al., 2000). According to the

\section{E. coli 0157}

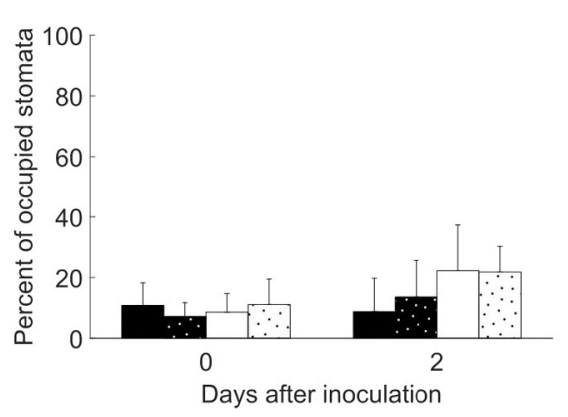

absolute number of attached/internalized Salmonella on the cut edges (with a smaller surface) in comparison with the lettuce disc, it may be that Salmonella attached/internalized preferentially to the cut edges. In contrast, Takeuchi et al. (2000) reported that Salmonella attached equally to the cut edge and the intact surface, strain variation seems thus possible. With confocal microscopy both pathogens were visualized in the parenchyma close to the cut edge. When studying the surface, high densities of bacteria were found, but both pathogens behaved similar and were never able to reach the parenchyma through the stomata, they were only found in the substomatal cavities. These results were expected as Kroupitski et al. (2009a) showed already that internalization did not (often) occur in the dark or at low temperature for Salmonella. They reported internalization in around $10 \%$ of the observed fields both at low light $\left(3 \mu \mathrm{E} \mathrm{m}^{-2} \mathrm{~s}^{-1}\right)$ in combination with low storage temperature $\left(4^{\circ} \mathrm{C}\right.$ ) and also when the lettuce was stored in the dark (at $30^{\circ}$

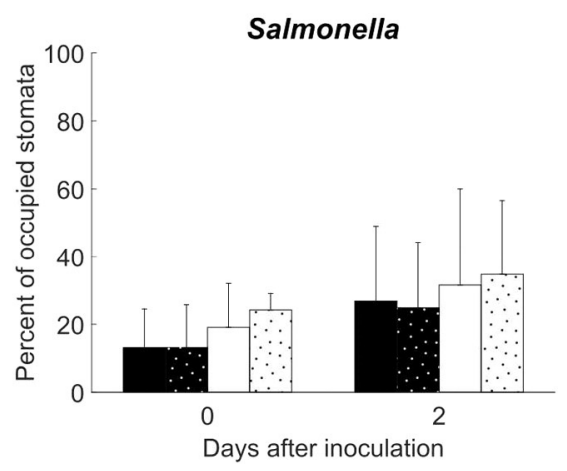

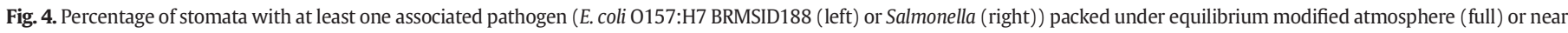

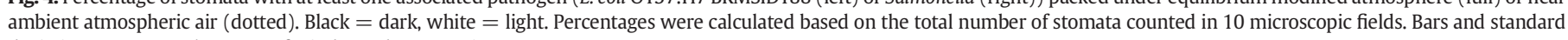
deviations represent the mean of 5 independent experiments. 


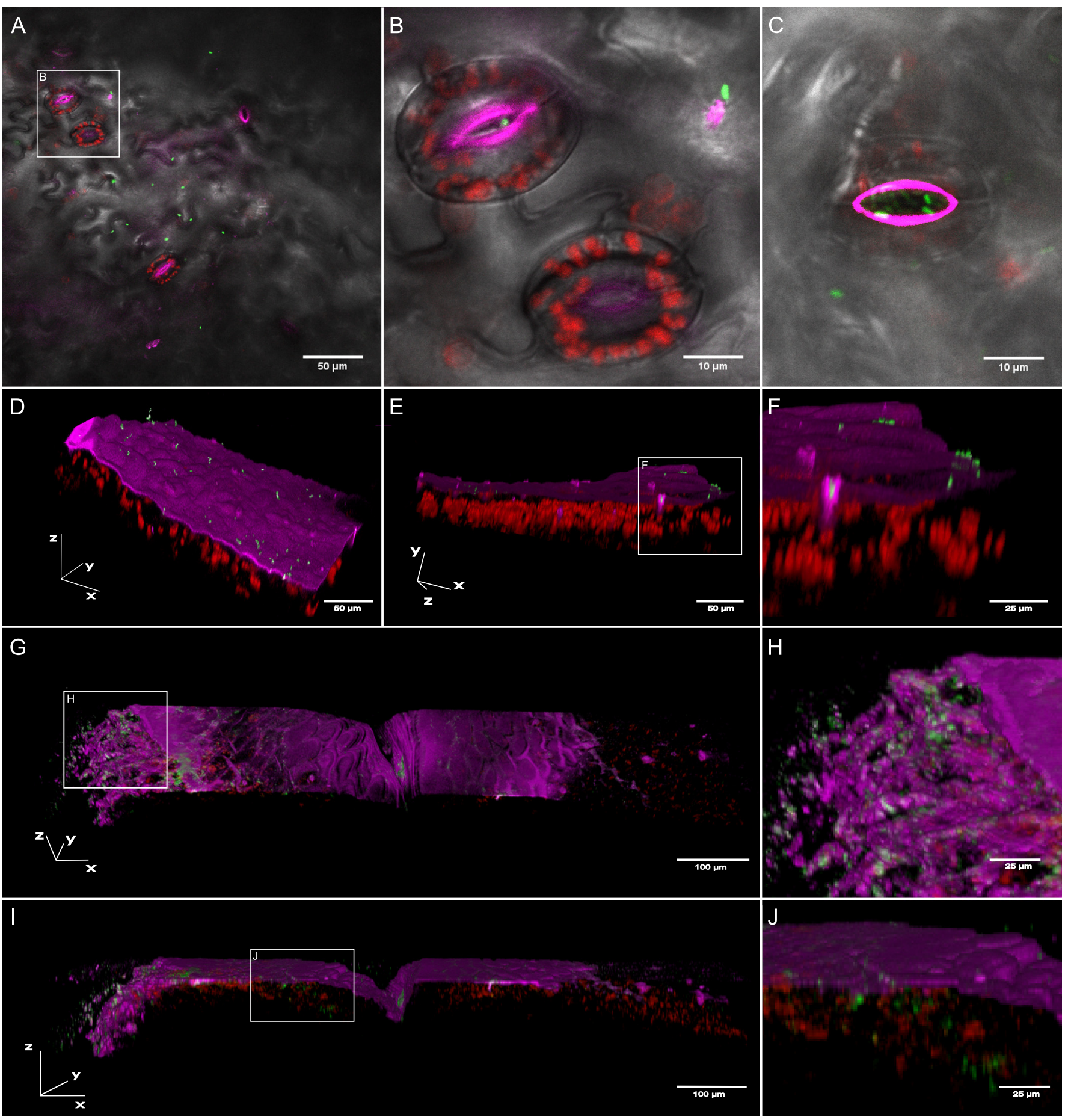

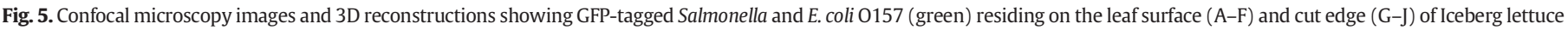

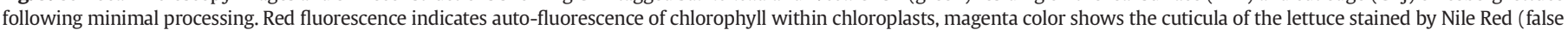

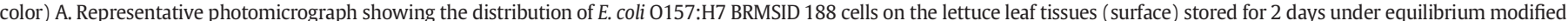

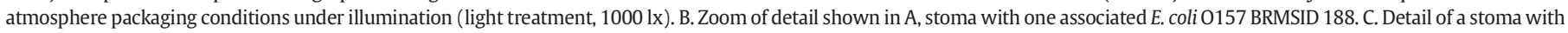

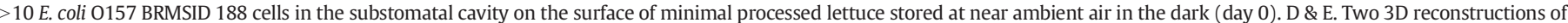

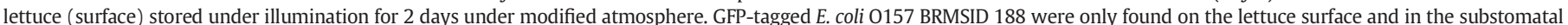

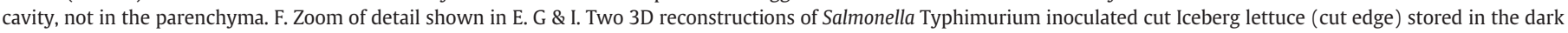

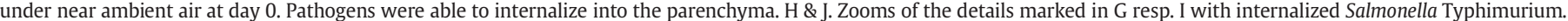
(For interpretation of the references to color in this figure legend, the reader is referred to the web version of this article.)

C). In our experiment, the storage temperature $\left(7{ }^{\circ} \mathrm{C}\right)$ was slightly higher and the exposure/storage time longer (up to 2 days in comparison with $2 \mathrm{~h}$ ), from which higher internalization may be predicted. An unknown factor, however, is the light that could reach the inoculated lettuce pieces. These lettuce pieces were packed together with the rest of the cut lettuce to reach about a total weight of $50 \mathrm{~g}$, but they were presumably not fully exposed to the light source (around $13.5 \mu \mathrm{E} \mathrm{m}^{-2} \mathrm{~s}^{-1}$ ) or at least not to its full intensity. Other reasons for the absence of internalization may be the fact that the other lettuce pieces in the bag may also have leaked nutrients, which might inhibit 


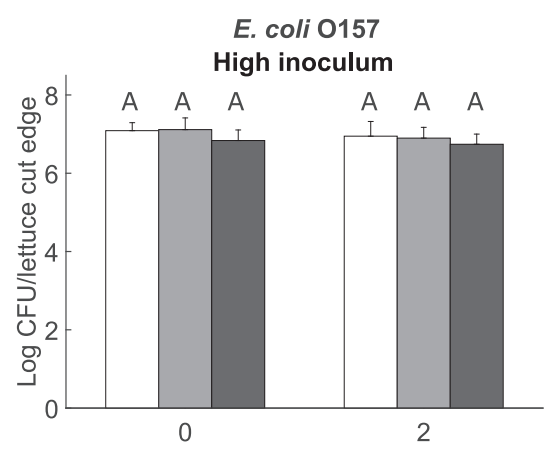

Days after inoculation

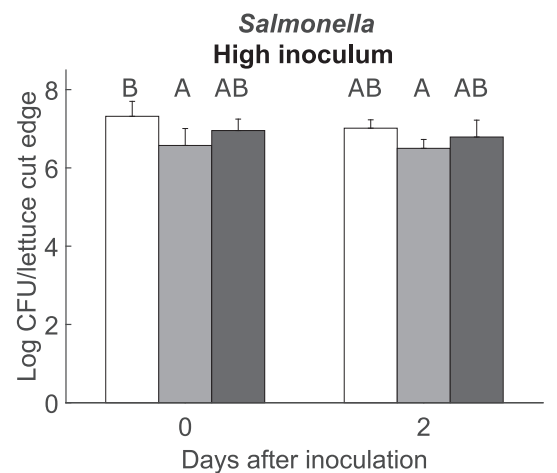

E. coli 0157

Low inoculum

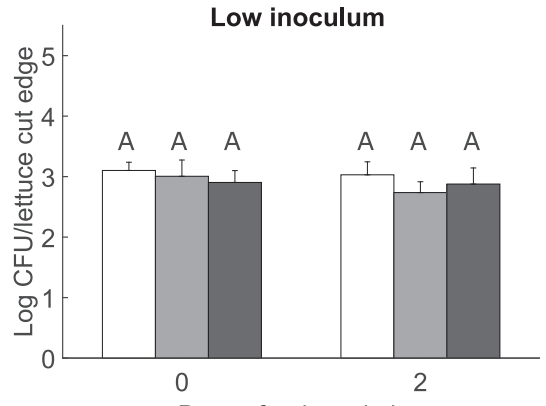

Days after inoculation

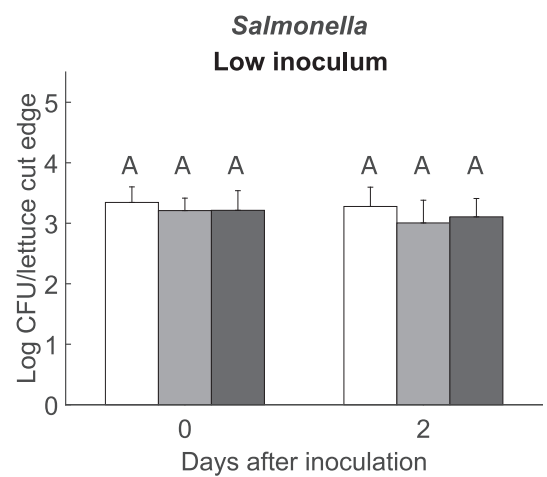

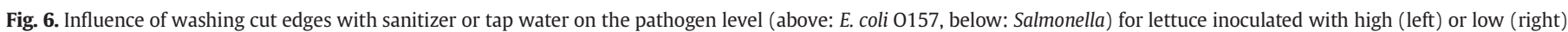

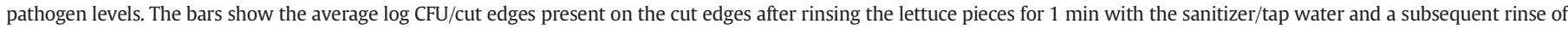

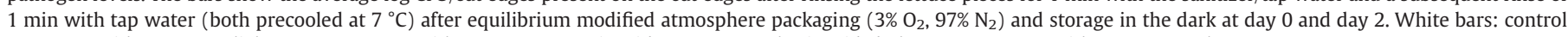
treatment with tap water, light grey: treatment with $40 \mathrm{mg} / \mathrm{L}$ peracetic acid + $1143 \mathrm{mg} / \mathrm{L}$ lactic acid, dark grey: treatment with $40 \mathrm{mg} / \mathrm{L} \mathrm{NaClO}$.

internalization. Kroupitski et al. (2009a) showed that the presence of exogenous nutrients can inhibit internalization as there is no need for the pathogens to search for other nutrients (Kroupitski et al., 2009a). Furthermore, we cannot exclude that the stomata were closed in the bag given the low metabolic state of the lettuce at low temperatures. The stomata were open during the observation of the lettuce under the microscope, but it may be induced by the sample preparation (e.g. submersion of the sample, illumination of the microscope, room temperature in microscopy room). A study of the status of stomatal opening/closure could have been done by making a classical stomatal print. Internalization seems also to depend on the lettuce type and cultivar (Golberg et al., 2011). The results of our study are limited to lettuce stored at appropriate cold storage temperatures $\left(7^{\circ} \mathrm{C}\right)$. As Kroupitski et al. (2009a) has shown that internalization occurs more frequently at higher temperatures, it should be very interesting for future research to study higher temperatures and longer storage periods corresponding with time and temperature abuses. Finally, our results of internalization through stomata showed a large variability between the different independent repeats. Lettuce variety, maturity and seasonal effects throughout the time period of the experiments (November-April) may have influenced the plant physiology of the Iceberg lettuce leaves and thus the internalization of the pathogen's cells. Indeed, young lettuce leaves produce more nutrients (Brandl and Amundson, 2008), but we tried to minimize this effect by selecting Iceberg heads with uniform maturity stage based on the chart of maturity stages of Iceberg lettuce and selecting leaves with the same developmental stage for sample preparation. Furthermore, as the lettuce was store bought it could not be guaranteed that all the heads belonged to the same variety, it has already been shown that enteric pathogens may interact differently with different lettuce cultivars (Klerks et al., 2007; Quilliam et al., 2012). Although small differences were detected with respect to the association of the pathogens with the stomata (e.g. influence of storage time), this effect is not of much importance for the industry as seemingly the cut edges are the main harbor place for pathogens.
Our results indicated that the concentrations of sanitizers investigated in the present study are not effective in substantially reducing the pathogen's numbers on the cut edges. This is in agreement with literature (Erickson, 2012) and with the fact that, particularly in Europe, the use of sanitizers is mainly recommended to keep the wash water clean rather than to decontaminate the lettuce (Baert et al., 2009; Velazquez et al., 2009; Zhang et al., 2009). Our results indicated that subsequent storage of treated lettuce (PAA + $\mathrm{LA}$ or $\mathrm{NaClO}$ ) under modified atmosphere at $7{ }^{\circ} \mathrm{C}$ revealed no significant influence of the pathogen level on the lettuce, which was is in accordance with the work of Posada-Izquierdo (Posada-Izquierdo et al., 2012) nor regarding the attachment/internalization of the bacteria. Our study indicates that various storage conditions (modified atmosphere or NAA, in the dark or exposure to light) of either water washed or sanitizer treated $(\mathrm{PAA}+\mathrm{LA}$ or $\mathrm{NaClO})$ fresh-cut Iceberg lettuce had no substantial influence on the survival, internalization and attachment of Salmonella and $E$. coli 0157 cells on the lettuce leaves (surface or cut-edge). Although, no big differences in behavior were found between the different tested conditions, a quantitative microbial risk assessment can only be made accurately when also the effect on the pathogen virulence (e.g. toxin expression, acid resistance, etc.) between the different conditions is investigated such as e.g. done by Oliveira et al. (2011). With this information, also the likelihood and severity of an infection can be predicted more precisely. The present study also confirmed that internalization of Salmonella Typhimurium and E. coli 0157 in fresh-cut Iceberg lettuce is most likely to occur at the cut edges and wounded tissue.

\section{Acknowledgements}

We would like to thank Elien Verguldt for technical assistance. This research was conducted within the framework of the EU FP7 Veg-itrade project 'Impact of Climate Change and Globalization on Safety of Fresh Produce - Governing a Supply Chain of Uncompromised Food Sovereignty' (www.veg-i-trade.org, grant agreement no. 244994). K. 
R. Avalos Llano thanks the Consortium EuroTANGO II, financed by the European Commission and managed by EACEA within the Framework of the Erasmus Mundus Action 2-Strand 1, for the postdoctoral scholarship. This work was funded partly by the Hercules foundation (AUGE013).

\section{Appendix A. Supplementary data}

Supplementary data to this article can be found online at http://dx. doi.org/10.1016/j.ijfoodmicro.2016.07.029.

\section{References}

Baert, L., Vandekinderen, I., Devlieghere, F., Van Coillie, E., Debevere, J., Uyttendaele, M., 2009. Efficacy of sodium hypochlorite and peroxyacetic acid to reduce murine norovirus 1, B40-8, Listeria monocytogenes, and Escherichia coli 0157:H7 on shredded iceberg lettuce and in residual wash water. J. Food Prot. 72, 1047-1054.

Brandl, M.T., Amundson, R., 2008. Leaf age as a risk factor in contamination of lettuce with Escherichia coli 0157:H7 and Salmonella enterica. Appl. Environ. Microbiol. 74, 2298-2306.

Burke, L.M., Brozel, V.S., Venter, S.N., 2008. Construction and Evaluation of a Gfp-Tagged Salmonella Typhimurium Strain for Environmental Applications.

Chua, D., Goh, K., Saftner, R.A., Bhagwat, A.A., 2008. Fresh-cut lettuce in modified atmosphere packages stored at improper temperatures supports enterohemorrhagic $E$. coli isolates to survive gastric acid challenge. J. Food Sci. 73, M148-M153.

Dinu, L.D., Bach, S., 2011. Induction of viable but non-culturable Escherichia coli 0157:H7 on the phyllosphere of lettuce: a food safety risk factor. Appl. Environ. Microbiol. 77 $8295-8302$.

Erickson, M.C., 2012. Internalization of fresh produce by foodborne pathogens. Annu. Rev. Food Sci. Technol. 3, 283-310.

Golberg, D., Kroupitski, Y., Belausov, E., Pinto, R., Sela, S., 2011. Salmonella Typhimurium internalization is variable in leafy vegetables and fresh herbs. Int. J. Food Microbiol. $145,250-257$.

Gu, G., Cevallos-Cevallos, J.M., van Bruggen, A.H.C., 2013. Ingress of Salmonella enterica Typhimurium into tomato leaves through hydathodes. PLoS One 8, e53470.

Horev, B., Sela, S., Vinokur, Y., Gorbatsevich, E., Pinto, R., Rodov, V., 2012. The effects of active and passive modified atmosphere packaging on the survival of Salmonella enterica serotype Typhimurium on washed romaine lettuce leaves. Food Res. Int. $45,1129-1132$.

Klein, S., Tian, A., Witmer, J., DeWaal, C.S., 2009. The FDA Top Ten: The Riskiest Foods Regulated by the US Food and Drug Administration. The Center for Science in the Public Interest.

Klerks, M.M., Franz, E., van Gent-Pelzer, M., Zijlstra, C., van Bruggen, A.H., 2007. Differential interaction of Salmonella enterica serovars with lettuce cultivars and plant-microbe factors influencing the colonization efficiency. ISME J. 1, 620-631.

Kroupitski, Y., Golberg, D., Belausov, E., Pinto, R., Swartzberg, D., Granot, D., Sela, S., 2009a. Internalization of Salmonella enterica in leaves is induced by light and involves chemotaxis and penetration through open stomata. Appl. Environ. Microbiol. 75, 6076-6086.

Kroupitski, Y., Pinto, R., Brandl, M.T., Belausov, E., Sela, S., 2009b. Interactions of Salmonella enterica with lettuce leaves. J. Appl. Microbiol. 106, 1876-1885.

Lopez-Galvez, F., Ragaert, P., Palermo, L.A., Eriksson, M., Devlieghere, F., 2013. Effect of new sanitizing formulations on quality of fresh-cut iceberg lettuce. Postharvest Biol. Technol. 85, 102-108.

Oliveira, M., Wijnands, L., Abadias, M., Aarts, H., Franz, E., 2011. Pathogenic potential of Salmonella Typhimurium DT104 following sequential passage through soil, packaged fresh-cut lettuce and a model gastrointestinal tract. Int. J. Food Microbiol. 148, 149-155.

Posada-Izquierdo, G.D., Pérez-Rodríguez, F., López-Gálvez, F., Allende, A., Selma, M.V., Gil, M.I., Zurera, G., 2012. Modelling growth of Escherichia coli 0157:H7 in fresh-cut lettuce submitted to commercial process conditions: chlorine washing and modified atmosphere packaging. Food Microbiol. 33, 131-138.

Quilliam, R.S., Williams, A.P., Jones, D.L., 2012. Lettuce cultivar mediates both phyllosphere and rhizosphere activity of Escherichia coli 0157:H7. PLoS One 7, e33842.

Semenov, A.V., van Overbeek, L., Termorshuizen, A.J., van Bruggen, A.H., 2011. Influence of aerobic and anaerobic conditions on survival of Escherichia coli 0157:H7 and Salmonella enterica serovar Typhimurium in Luria-Bertani broth, farm-yard manure and slurry. J. Environ. Manag. 92, 780-787.

Seo, K.H., Frank, J.F., 1999. Attachment of Escherichia coli 0157:H7 to lettuce leaf surface and bacterial viability in response to chlorine treatment as demonstrated by using confocal scanning laser microscopy. J. Food Prot. 62, 3-9.

Sharma, M., Lakshman, S., Ferguson, S., Ingram, D.T., Luo, Y.G., Patel, J., 2011. Effect of modified atmosphere packaging on the persistence and expression of virulence factors of Escherichia coli 0157:H7 on shredded iceberg lettuce. J. Food Prot. 74, 718-726.

Takeuchi, K., Frank, J.F., 2001. Quantitative determination of the role of lettuce leaf structures in protecting Escherichia coli 0157:H7 from chlorine disinfection. J. Food Prot. 64, 147-151

Takeuchi, K., Matute, C.M., Hassan, A.N., Frank, J.F., 2000. Comparison of the attachment of Escherichia coli 0157:H7, Listeria monocytogenes, Salmonella typhimurium, and Pseudomonas fluorescens to lettuce leaves. J. Food Prot. 63, 1433-1437.

Takeuchi, K., Hassan, A.N., Frank, J.F., 2001. Penetration of Escherichia coli 0157:H7 into lettuce as influenced by modified atmosphere and temperature. J. Food Prot. 64, 1820-1823.

Van der Linden, I., Cottyn, B., Uyttendaele, M., Vlaemynck, G., Maes, M., Heyndrickx, M., 2014. Evaluation of an attachment assay on lettuce leaves with temperature- and starvation-stressed Escherichia coli 0157:H7 MB3885. J. Food Prot. 77, 549-557.

Velazquez, L.D., Barbini, N.B., Escudero, M., Estrada, C., de Guzman, A.M.S., 2009. Evaluation of chlorine, benzalkonium chloride and lactic acid as sanitizers for reducing Escherichia coli 0157:H7 and Yersinia enterocolitica on fresh vegetables. Food Control 20, 262-268.

Zhang, G.D., Ma, L., Phelan, V.H., Doyle, M.P., 2009. Efficacy of antimicrobial agents in lettuce leaf processing water for control of Escherichia coli 0157:H7. J. Food Prot. 72. 1392-1397. 